\title{
Self-Care Capacities of Diabetic Patients Monitored in the Internal Medicine Unit at the Kara Teaching Hospital (CHU Kara)
}

\section{Toyi Tchamdja1,2*, Abago Balaka1,3, Kodjo Agbéko Djagadou ${ }^{1,3}$, Djalogue Lihanimpo ${ }^{1,2}$, Mohaman Awalou Djibril1,3}

${ }^{1}$ Service de Médecine Interne, Kara, Lomé, Togo

${ }^{2}$ Faculté des Sciences de Santé, Université de Kara, Kara, Lomé, Togo

${ }^{3}$ Faculté des Sciences de Santé, Université de Lomé, Kara, Lomé, Togo

Email: ^ttpault234@gmail.com

How to cite this paper: Tchamdja, T., Balaka, A., Djagadou, K.A., Lihanimpo, D. and Djibril, M.A. (2020) Self-Care Capacities of Diabetic Patients Monitored in the Internal Medicine Unit at the Kara Teaching Hospital (CHU Kara). Open Journal of Internal Medicine, 10, 103-111. https://doi.org/10.4236/ojim.2020.102011

Received: December 7, 2019

Accepted: March 29, 2020

Published: April 1, 2020

Copyright $\odot 2020$ by author(s) and Scientific Research Publishing Inc. This work is licensed under the Creative Commons Attribution International License (CC BY 4.0).

http://creativecommons.org/licenses/by/4.0/

\begin{abstract}
Objectives: To evaluate the practice of self-care in diabetic patients monitored at the Kara Teaching Hospital, known as CHU Kara. Method: We conducted a quantitative, descriptive and cross-sectional study of 40 diabetic patients monitored at the Kara CHU. The data collection took place from February 20 to May 28, 2018 and the data was collected anonymously. Results: Out of the forty (40) respondents, $60 \%$ were male with a sex ratio of 1.5 and an average age of 56.15 years. Two-thirds (2/3) of the patients did not have the blood glucose meter. More than half (52\%) did not know the normal blood glucose value and $82.5 \%$ were on a low carbohydrate diet. Eighty-two point fifty percent $(82.50 \%)$ were under Oral antidiabetic (ADO). Forty percent $(40 \%)$ of patients often forgot their medication. Forty-seven point-fifty percent reported frequent episodes of hypoglycaemia with dizziness (58\%), tremors (53\%), hunger (53\%), sweat (37\%), tingling (26\%) and the most common gestures were: sugar ingestion (53\%) and glycemic control (26\%). Eighty-five (85\%) said they used to feel hyperglycemia with fatigue (76\%), polyuria $(65 \%)$, polydipsia (44\%) the most common precursors and the most frequent interventions were taking hypoglycemic drugs (74\%) and controlling blood glucose (24\%). Conclusion: The practice of self-care remains risky for diabetic patients. Hence the need for the establishment of adequate therapeutic education programs.
\end{abstract}

\section{Keywords}

Self-Care, Diabetic Patient, The Kara CHU 


\section{Introduction}

Diabetes, a non-communicable and chronic disease, is a public health concern because of its increasing frequency over the world. The International Diabetes Federation (IDF) estimated in 2003 to 194 million the number of people living with diabetes in the world of which nearly $2 / 3$ resided in developing countries [1] against 425 million in 2017 [2]. For example, the WHO forecasts 622 million diabetics by 2040 [2]. It kills more than 3.8 million people each year [3]. In 2015, it caused 5 million deaths worldwide [2]. In Africa, at the beginning of the $20^{\text {th }}$ century, diabetes was rare; but these days, it is expanding because of the change in lifestyle and the longer life expectancy of the population. According to IDF estimates, 15.5 million adults aged 20 - 79 years old had diabetes in 2017 and this number is expected to increase by $162.5 \%$ by 2045 [2].

In Togo, the national survey of risk factors for non-communicable diseases carried out in 2010 revealed that the prevalence of diabetes was $2.6 \%$ among the population aged 15 to 64 [3]. This is a real public health concern. The increase in the prevalence of diabetes, its chronicity, its various complications and the complexity of its management require the total involvement of diabetic patients in the management of their pathology. In fact, self-care accounts for $98 \%$ of diabetes care [4]. Regular self-care practices including healthy eating habits, regular exercise program, weight management, self-monitoring of blood glucose, foot care, regular consultation with health professionals, and taking drugs are needed to control blood glucose in the long term [5]. The present study was conducted in order to determine the self-care capacity of diabetic people monitored at the Kara Teaching Hospital.

\section{Patients and Method}

The present study was carried out in the internal medicine department of the Kara Teaching Hospital. This was a quantitative, descriptive and cross-sectional study that took place from 20 February to 28 May 2018 at CHU-Kara. The study population consisted of diabetic patients followed at Kara CHU in 2018. Were included in this study:

- Any diabetic patient on treatment whose diabetes has been diagnosed for at least one year;

- Any diabetic patient available at the time of the survey;

- Any diabetic patient whose age is over 18 years.

The sample was determined by the Shwartz formula considering a margin of error of $5 \%$ and a confidence level of 1.96 so that our sample size was 38 patients in minimum. For data collection, a pre-established questionnaire was used. This questionnaire has been tested on five patients. This questionnaire is divided into 5 sections namely: socio-demographic data, competence related to the self-monitoring of blood glucose, competence related to the self-administration of drugs, competence related to self-management of discomfort, difficulties encountered by the patient in the management of their illness. The collection tech- 
nique was the direct interview with direct administration of the questionnaire. We used the software SPSS to analyse the data collected.

\section{Results}

\subsection{Socio-Demographic Data}

In total, 40 patients were surveyed. There was a male predominance with a sex ratio of 1.5. The average age of the patients surveyed was 56, 15 years old with age extremes ranging from 37 to 82 years. The most represented age group was (55 years old at 70 years old (45\%). The majority of the 40 patients surveyed (70\%) had been diagnosed. Less than 10 years. Nearly three-quarters (3/4) of the patients $(72.5 \%)$ had a family history of diabetes. Finally, apart from diabetes, 29 of the 40 surveyed (72.5\%) had another illness, with high blood pressure in the first place (93.10\%).

\subsection{Skills of Patients Related to the Self-Monitoring of Blood Glucose}

The survey found that $67.5 \%$ of diabetic patients did not have the glucometer. Eighty-four point sixty-one (84.61\%) were acquired less than 5 years ago. Of the $1 / 3$ of the patients who had the glucometer, more than half (54\%) were able to do the self-glycemic control.

This study showed that $32.5 \%$ of respondents checked their blood glucose once a month, followed by those who did it twice a month (27.5\%).

Of the 40 patients interviewed, $21 \%$ or $52.5 \%$ did not know the normal value of blood glucose.

Once blood glucose was high, the most common disposition was taking hypoglycemic drugs (28) (Table 1).

But when the glycemia was low $52.5 \%$ of respondents were unaware of the right attitude to observe in case of low glycemia whereas $27.5 \%$ were re-regaring. Finally, the most common used measures to maintain the balance of glycemia were: A sugarless diet (33), respect for treatment (30), physical exercise (17) (Table 2).

\subsection{Competences Related to Self-Administration of Drugs}

This study revealed that 33 of the 40 patients surveyed, $82.5 \%$ were on oral antidiabetics, 4 were on combination of oral antidiabetics and insulin, and 3 were

Table 1. Distribution of respondents according to arrangements made in case of high blood sugar.

\begin{tabular}{ccc}
\hline & Frequency & Percentage (\%) \\
\hline Medication & 28 & 70 \\
Consultation & 12 & 30 \\
Physical exercise & 5 & 13 \\
Reconsideration of diet & 2 & 5 \\
Forgetting the appropriate rules & 2 & 5 \\
\hline
\end{tabular}


on insulin alone. The majority of respondents who were on insulin (86\%) were unable to receive the injection. In terms of managing side-effects, 31 or $77.5 \%$ of patients said they had never had side-effects; eight patients (20\%) consulted a health worker after the treatment was stopped and one (2.5\%) patient used self-medication. Skills related to the self-management of hypoglycemic and hyperglycemic discomforts.

Of the 40 respondents, almost half (47.5\%) often felt hypoglycemia-related discomfort. The most common warning signs of hypoglycemia were vertigo (57, $89 \%)$, tremors (52.63\%) and hunger (52.63\%) as shown in Table 3.

Regarding these signs of hypoglycaemia, patients frequently resorted to resugaring (52.63\%) and blood sugar control (26.32\%). Hyperglycemic discomforts were often seen by $85 \%$ of patients. The most common warning signs of hyperglycemia during the survey were: fatigue $(76.47 \%)$, polyuria (64.71\%), and polydipsia (44.12\%) (Table 4).

Table 2. Distribution according to measures to maintain the balance of glycemia.

\begin{tabular}{ccc}
\hline & Frequency & Percentage (\%) \\
\hline Hypoglycemic diet & 33 & 82.50 \\
Observance of treatment & 30 & 75 \\
Physical exercise & 17 & 42,50 \\
Nothing & 1 & 2,50 \\
\hline
\end{tabular}

Table 3. Distribution of respondents according to the warning signs of hypoglycemia.

\begin{tabular}{ccc}
\hline & Frequency & Percentage (\%) \\
\hline Dizziness & 11 & 57.89 \\
Shaking & 10 & 52.63 \\
Hunger & 10 & 52.63 \\
Sweating & 7 & 36.84 \\
Tinkling & 5 & 26.32 \\
Unsteadiness & 3 & 15.79 \\
Behavioural disorder & 2 & 10.53 \\
Palpitations & 1 & 5.26 \\
Anxiety & 1 & 5.26 \\
\hline
\end{tabular}

Table 4. Distribution according to the warning signs of hyperglycemia.

\begin{tabular}{ccc}
\hline & Frequency & Percentage (\%) \\
\hline Fatigue & 26 & 76.47 \\
Polyuria & 22 & 64.71 \\
Polydipsia & 15 & 44.12 \\
Drowsiness & 10 & 29.41 \\
\hline
\end{tabular}


The taking of hypoglycemic drugs (73.53\%), blood sugar control (23.53\%) and the consultation of a health care practitioner (23.53\%) were common practices to treat these hyperglycemic discomforts.

\section{Discussion}

This study was done to evaluate the practice of self-care in diabetic patients monitored at the Kara Teaching Hospital. The present study has some limitations. There is thus a bias in recruitment and selection. However, the size of the sample, the site where the study was carried out and the inclusion criteria gives the study strength and replicability.

\subsection{Sociodemographic Data}

This study revealed that $60 \%$ of patients were male with a sex ratio of 1.5 . This male predominance may be due to the fact that men may be less sensitive to insulin than women or tend to store fat around their organs, rather than under the skin as in women. These results are similar to those of the Regional Health Agency (ARS) Île-de-France in the Study of Drug Compliance of Type II Diabetes Patients in September 2016, which found a male predominance of 58\% [6].

In this study, the average age was 56, 15 years with age extremes ranging from 37 to 82 years. The most represented age group was between [age 55 and 70]. These results could be explained by the fact that the risk of diabetes increases with age. These results are in line with those of Fehaima, which, in its study on quality of life and diabetes in Algeria, in 2017, found the average age at $54.19 \pm$ 17.94 years, the most represented age group was that between the ages of 45 and $60(30 \%)$ and the extremes of age ranging from 16 to 86 years [7] and Wanvoegbe et al., who, in their study on the assessment of therapeutic compliance among diabetics in Benin, had a mean age of $54.67 \pm 12.69$ years [8].

The majority of respondents (70\%) were diagnosed less than 10 years ago. This is explained by the fact that the diagnosis of diabetes is often at a late stage since it is a silent disease. This result is similar to that of Dekkar in Morocco, in 2012, which, in its study on Diabetic Patient Therapeutic Education, had obtained $69 \%$ of those diagnosed less than 10 years ago [9].

Family diabetes was found in $72.5 \%$ of our respondents, which is explained by the fact that heredity is a risk factor for diabetes. This result is consistent with that of Mansour in Morocco who, in his thesis on the study of factors, associated with complications in diabetics in 2012 had found $65.63 \%$ [10]. This study revealed the notion of comorbidity in $72.5 \%$ of respondents and the most common pathology was high blood pressure (93.10\%). This predominance of hypertension could be explained by the fact that it is a risk factor for the occurrence of diabetes and vice versa. Fehaima in their study had obtained 55.66\% as the comorbidity rate with HTA as the most common pathology (42.45\%) [7]. 


\subsection{Skills Related to Self-Monitoring of Blood Sugar}

In this series, $32.5 \%$ of the 40 patients had the glucometer. This result is in disagreement with that of Fournier et al. in France in a report concerning: information and education received by diabetics, the educational practices of physicians, as well as the expectations of people with diabetes and doctors in December 2011, which had obtained $99.63 \%$ [11]. This discrepancy is explained by the very low socioeconomic level and health coverage by health insurance which is limited to civil servants in Togo (developing country).

Fifty-four percent $54 \%$ of those who had the glucometer were able to self-monitor the blood glucose. Fournier et al. had obtained 85\% [11]. This is due to the high illiteracy rate in developing countries and especially the lack of therapeutic education.

This study showed that $32.5 \%$ of respondents checked blood glucose once a month, $27 \%$ did so twice a month. This could be explained by the fact that the majority of the respondents in this study (67.5\%) did not have the glucometer, the lack of financial means for regular monitoring of blood glucose, forgetfulness, travel, practical difficulties and lack of knowledge about the importance of regular monitoring of glycemic values. Karter et al. in the United States of America in a study on self-monitoring of blood glucose in 2000, and Lecomte et al. in France in their study on self-monitoring of blood glucose in people with type 1 and type 2 diabetes living in France, found respectively 60\% of type 1 diabetics who reported a lower ASG frequency than that recommended by the ADA (greater than or equal to 3 times a day) [12]; and $42 \%$ of type 1 diabetic patients and $65 \%$ of insulin-treated type 2 diabetics who self-monitored less than 3 times daily [13].

Among the 40 patients surveyed, $80 \%$ often had a glycemic value greater than $1.26 \mathrm{~g} / \mathrm{l}$ against $20 \%$ who maintained it at $1.26 \mathrm{~g} / \mathrm{l}$ or below, which means that diabetes is poorly-balanced in the patients surveyed. This hyperglycemia is responsible for both metabolic and degenerative complications. In fact, in addition to glycemic control, it is recommended to measure the HbAlc level every 3 to 4 months; given the scarcity of this practice in our hospitals and the cost, this is hardly done. This reality of glycemic imbalance was reported by Dekkar who obtained $72 \%$ of patients whose diabetes was poorly-balanced by the control of glycated hemoglobin ( $\mathrm{HbAlc}>7 \%$ ) [9], as well as Wanvoegbe and al. obtained glycosylated hemoglobin greater than or equal to $7 \%$ in $77 \%$ of their respondents [8].

\subsection{Skills Related to Self-Administration of Drugs}

In this series, $82.5 \%$ of the respondents were under oral antidiabetic, $10 \%$ were under the combination of insulin and oral antidiabetic and $7.5 \%$ under insulin. These results are similar to those of Fehaima, which obtained 36\% of patients under oral antidiabetic, $33 \%$ under insulin and $29 \%$ under the combination of both [7]. These results could be explained by the fact that type 2 diabetes is the most 
widespread and that the most common treatment is the use of oral antidiabetic of the $17.5 \%$ of respondents who were under insulin, only $14 \%$ were able to inject insulin. This result contrasts with that of Hamon in a Practice Survey on the technique of injecting insulin in France in 2014, which had obtained 52.4\% of patients who were able to be injected [14]. This discrepancy is due to the lack of programs of Therapeutic Education of the Patient and illiteracy in our environment. In a study conducted in Morocco on the factors influencing the use of insulin therapy in type 2 diabetics, at the level of primary health care institutions by Milouda in 2017, the main difficulties related to self-injection reported by the interviewees were mainly physical dependence (inability to fill the syringe and/or injecting insulin), injection pain, hypoglycemic discomfort caused by insulin [15] Forty percent $(40 \%)$ of the respondents said they often forgot their medication and the most common causes of this oversight were profession and travel. These results could be explained by the predominance of merchants in our study sample who have to travel from time to time to purchase or sell items. This rate of forgetfulness is in line with that of Dekkar who obtained $44 \%$ of those who forgot 1 to 4 times a month [9].

\subsection{Skills Related to the Self-Management of Discomforts}

Forty-seven point five percent (47.5\%) of the respondents often felt the discomfort of hypoglycemia. This percentage of respondents who claimed to have perceived hypoglycemic discomfort would be due either to the lack of awareness of hypoglycemic symptoms or to the fact that the diabetes is not balanced in most patients and it is infrequent that they contract it. As a result of these discomforts, patients made frequent use of the re-sugaring and the blood sugar control. (According to the data of the study, the actions to take in case of these symptoms are: to stop any activity, to check if possible the capillary glycaemia to confirm hypoglycemia, to add sugar to one's diet (3 lumps of sugar or a glass of fruit juice. or two low-teaspoons of jam or honey), investigate the causes to prevent this from happening again and/or to adjust its treatment [16]. The present study also found that $85 \%$ of patients often recognized hypoglycaemic discomforts. These results are understandable because the diabetes is not balanced in most patients whereas the glycemia is often high. In case of these discomforts, taking of hypoglycemic medicines consultation and control of blood glucose were common practices. Consequently, authors recommend blood glucose control. If blood sugar is $\geq 2.50 \mathrm{~g} / \mathrm{l}$, and acetone is tested in the urine there is an emergency. In this case, notify the physician or inject insulin as recommended by the physician $[16]$.

\section{Conclusion}

Diabetes is a global public health concern because of its prevalence and high mortality rate as well as its heavy medical and socio-economic consequences. To prevent or delay these complications, patients must develop skills to manage and 
check their health and treatment. The study found that $82.5 \%$ of patients were not self-monitoring blood sugar, $86 \%$ of those who were under insulin were unable to inject themselves, $37 \%$ were unable to manage hypoglycemic discomforts, $42 \%$ were unable to manage hyperglycemic discomforts. Improving the therapeutic education of patients will enable a better knowledge of self-care by patients with diabetes.

\section{Conflicts of Interest}

The authors declare no conflicts of interest regarding the publication of this paper.

\section{References}

[1] Fédération Internationale du Diabète, Région Afrique (2005) Guide de prise en charge du diabète de type 2 pour l'Afrique sub-saharienne.

[2] (2017) Atlas du Diabète de la Fédération Internationale du Diabète. 8th Edition. http://www.diabetesatlas.org

[3] Fond-Harmant, L. (2011) Programmes de lutte contre le diabète dans six pays européens et au Canada. Santé Publique, 23, 41-53.

https://doi.org/10.3917/spub.111.0041

[4] Programme National de Lutte contre les Maladies Non Transmissibles-Togo (PNMNT-TOGO) (2012) Plan stratégique intégré de lutte contre les maladies non transmissibles 2012-2015.

[5] Lafontaine, S. (2015) Le soutien de l'autosoin d'adultes vivant avec le diabète de type 2 [Essai]. Québec: Université de Sherbrook Sciences Infirmières.

[6] Agence Régionale de Santé Île-de-France (2016) Etude de l'observance médicamenteuse des patients diabétiques de type II en Île-de-France.

[7] Fehaima, S. (2016-2017) Qualité de vie et diabète [Mémoire de fin d'étude en vue d'obtention du Diplôme de Docteur en médecine]. CHU Tlemcen-service de médecine interne; Année universitaire, Tlemcen.

[8] Wanvoegbe, F.A., Agbodande, K.A., Alassani, A., Aviansou, A., Gninkoun, J., Amoussou-Guenou, D., Djrolo, F., Zannou, M. and Houngbe, F. (2018) Evaluation de l'observance thérapeutique chez les diabétiques au Bénin. Médecine d Afrique Noire, 7, 355-361.

[9] Dekkar, O. (2012) L'éducation thérapeutique du patient diabétique (pratiques et messages éducatifs) [thèse pour l'obtention du doctorat en médecine]. Université Sidi Mohammed Ben Abdellah Faculté de Médecine et de Pharmacie, Maroc.

[10] Mansour, K. (2013) Etude des facteurs associés aux complications Chez les diabétiques du RSSB Préfecture des arrondissements de Ben Msik Année 2012 [Mémoire de fin d'études pour le cycle de Master]. Ecole Nationale de Santé Publique Filière: Epidémiologie de Santé Publique, Rabat.

[11] Fournier, C., et al. (2011) Rapport concernant: L'information et l'éducation reçues par les personnes diabétiques, les pratiques éducatives des médecins, ainsi que les attentes des personnes diabétiques et des médecins. France: Etude ENTRED 2007-2010.

[12] Karter, A.J., et al. (2000) Self-Monitoring of Blood Glucose: Language and Financial Barriers in a Managed Care Population with Diabetes. Diabetes Care, 23, 477-483.

https://doi.org/10.2337/diacare.23.4.477 
[13] Lecomte, P., et al. (2008) Self-Monitoring of Blood Glucose in People with Type 1 and Type 2 Diabetes Living in France: The Entred Study 2001. Diabetes \& Metabolism, 34, 219-226. https://doi.org/10.1016/j.diabet.2007.11.005

[14] Hamon, E. (2014) Enquête de pratique sur la technique d'injection de l'insuline en France, en 2014. HIA Bégin, service d'Endocrinologie, Saint-Mandé, France.

[15] Milouda, I. (2017) Les facteurs influençant l'utilisation de l'insulinothérapie chez les diabétiques type 2 au niveau des établissements de soins de santé primaires Cas de la préfecture de sale [Mémoire de fin d'études]. Ecole Nationale de Santé Publique cycle de spécialisation en sante publique et en management de la sante, Rabat.

[16] Lilly France (2018) Mémo hypoglycémie-hyperglycémie. http://www.lilly.fr 